ing a mathematical simulation method to build an upper dental arch diagram for primary occlusion. The technique is based on the regularities of the circle geometry, where the diameter is defined as the ratio of the arch width between the canines and the central angle sine. The value of the central angle here, according to the circle geometry laws, was the ratio of the arch depth double arctangent to the width between the primary canines. Overlapping the diagram on the upper dental arch model showed their match, which allowed applying the method of arch constructing in clinical orthodontic practice.

\section{REFERENCES}

1. DMitrienko S.V., Domenyuk D.A., Vedeshina E.G. Shape individualization in lower dental arches drawn on basic morphometric features // Archiv EuroMedica, 2015. - Vol. 5. - № 1. - P. 11-15.

2. Domenyuk D.A., Vedeshina E.G., Dmitrienko S.V. Dynamics of changes in transverse and frontal- retromolar jaw sizes in children throughout the orthodontic treatment stages. Kubanskij nauchnyj medicinskij vestnik. 2016;(3):51-59. (In Russ.) DOI:10.25207/1608-6228-2016-3-51-59.

3. Domenyuk D.A., Shkarin V.V., Porfiriadis M.P., DMitrienko D.S., Dmitrienko S.V. Classification of facial types in view of gnathology // Archiv EuroMedica, 2017. - Vol. 7. - № 1. - P. 8-13.

4. DomenYuk, D.A. Modern classification of dental arches / D.A. Domenyuk, S.V. Dmitrienko // Archiv EuroMedica, 2014. - Vol. 4. - № 2. - P. 14-16.

5. Shkarin V.V., Domenyuk D.A., Porfiriadis M.P., DMitrienko D.S., DMitrienko S.V. Mathematical and graphics simulation for individual shape of maxillary dental arch // Archiv EuroMedica, 2017. - Vol. 7. - № 1. - C. 60-65.

6. ShKarin V.V., Porfiriadis M.P., Domenyuk D.A., DMitrienko D.S., DMitrienko S.V. Setting reference points for key teeth location in case of abnormal dental arch shape //Archiv EuroMedica. - 2017. - Vol. 7. - № 2. - P. 111-117.

\title{
DIAGNOSTIC VALUE OF CEPHALOMETRIC PARAMETERS AT GRAPHIC REPRODUCTION OF TOOTH DENTAL ARCHES IN PRIMARY TEETH OCCLUSION
}

\section{Alexander Lepilin, Igor Fomin, Dmitry Domenyuk, Sergei Dmitrienko, Gasan Budaychiev}

One of the significant and objective ways for diagnosing anomalies in the dentoalveolar system, as well as for controlling the treatment effectiveness and forecasting potential aesthetic changes in the face soft tissue base, implies studying the cephalometric parameters. Diagnosis is given based on clinical and radiological examination, as well as on studying control and diagnos-tic jaw models $[1,3]$. There are findings available, which show odontometry of infant teeth and linear parameters of dental arches, as well as methods have been proposed for graphic reproduc-tion of dental arches in view of individual features $[2,5]$.

The Schwarz method for designing a semicircle has been proposed, where the diameter is constituted by the width of the dental arch between the vestibular surfaces of the second primary molars. The specific features for constructing the dental arch of the primary occlusion have been shown, taking into account the lateral segment length, which includes the sizes of the primary molars and the canine. Notable are works claiming potential employment of the circle geometry regularities for constructing individual shape of dental arches in the permanent teeth occlusion, in view of their gnathic and dental types $[4,6]$. However, there is no data available on methods for diagnosing dentoalveolar anomalies in the primary teeth occlusion, taking into account the parameters of the facial part of the head.

Arm. Identifying the face and the dental arches basic parameters in children at their primary occlusion stage in order to develop methods for diagnosing maxillofacial anomalies.

Materials and methods. Anthropometric examination of the face and dental arches was carried out involving 67 children (aged 4-6) with a full set of primary teeth without signs of maxillofacial pathology. The anthropometric examination of the face was performed in the vertical direction from the superciliary point (g-glabella) to the nasal point of the subnasale (sn), and from that to the chin point gnathion (gn). This way the vertical dimensions were obtained for the middle (nasal) and lower (gnathic) part of the face. The transversal direction was used to 
identify the width of the face distal part between the zygomatic points (zy-zy). In the anterior part of the face, the distance between the most prominent alare (al-al) lateral points was measured. Biometric study of the jaw stone models implied evaluating the dental arches width between the canines and the second molars. The arches depth was measured from the interincisal point along the conventional midline of the arc that was perpendicular to the intermolar line. The depth of the anterior part was measured from the interincisal (central) point to the conventional line of the canine locus. The diagonal dimensions were taken from the central point to the point on the canine and up to the point on the second primary molar. Odontometric study was carried out identifying the length of the dental arch anterior section and the length of the entire dental arch, which was required for graphic reproduction of the primary occlusion dental arches. In the reproduction of arches, the circle diameter was taken as the design value equal to the ratio of the arch width between the canines to the central angle sine. In this case, the value of the central angle was the ratio of the double arctangent of the arch depth to its width.

Results AND Discussion. The maxillofacial study in the study groups has shown that in case of physiological occlusion, the vertical facial parameters measured from the g-point to the gn-point were $108.97 \pm 2.64 \mathrm{~mm}$. The height of the nasal $(\mathrm{g}$-sn) and the gnathic (sn-gn) parts of the face was $52.72 \pm 1.85$ $\mathrm{mm}$ and $52.96 \pm 1.95 \mathrm{~mm}$, respectively. The latitudinal facial parameters between the zygomatic points were $111.85 \pm 1.66 \mathrm{~mm}$. The width of the anterior face, measured between the nose wings, was $32.65 \pm$ $0.75 \mathrm{~mm}$. The biometric study of the jaw stone models revealed that the inter-canine transversal distance was $33.21 \pm 0.23 \mathrm{~mm}$, while between the second molars it was $49.79 \pm 0.41 \mathrm{~mm}$. The total arch depth (sagittal) was $25.56 \pm 0.31 \mathrm{~mm}$. The depth of the dental arch in the anterior part was $9.57 \pm 0.23 \mathrm{~mm}$. The anterior diagonal was $18.34 \pm 0.32 \mathrm{~mm}$, while the diagonal sizes of the dental arches (right and left) were, as a rule, identical $-35.52 \pm 0.45 \mathrm{~mm}$. obtained The anthropometric data offer some approximate, average statistical values for the major linear parameters. The most accurate idea of the upper dental arch shape can be obtained through graphic reproduction, which is based on measuring the relatively stable parameters of the dental arches. The outcomes of imposing an individual graphic reproduction on the upper jaw stone model has revealed full compliance of the dimensions at the physiological occlusion of the primary teeth, which can be used in the clinical orthodontics to diagnose anoma-lies and select the best treatment.
Conclusion. The anthropometric data from studying the face and the dental arches in the children of the study groups provide an idea of the approximate, average statistical parameters for the main linear parameters, whereas graphic reproduction of dental arches will allow deter-mining the individual maxillofacial features.

\section{REFERENCES}

1. DMitrienko S.V., Domenyuk D.A., Vedeshina E.G. Shape individualization in lower dental arches drawn on basic morphometric features // Archiv EuroMedica, 2015. - Vol. 5. - № 1. - P. 11-15.

2. Domenyuk, D.A. Modern classification of dental arches / D.A. Domenyuk, S.V. Dmitrienko // Archiv EuroMedica, 2014. - Vol. 4. - № 2. - P. 14-16.

3. Domenyuk, D.A. Correlation of dental arch major linear parameters and odontometric indices given physiological occlusion of permanent teeth in various face types / D.A. Domenyuk, E.G. Vedeshina, S.V. Dmitrienko // Archiv EuroMedica. - 2016. - T. 6. № 2. - P. 18-22.

4. Domenyuk D.A., Shkarin V.V., Porfiriadis M.P., DMitrienko D.S., DMitrienko S.V. Classification of facial types in view of gnathology // Archiv EuroMedica, 2017. - Vol. 7. - № 1. - P. 8-13.

5. ShKarin V.V., Porfiriadis M.P., Domenyuk D.A., Dmitrienko D.S., DMitrienko S.V. Setting reference points for key teeth location in case of abnormal dental arch shape //Archiv EuroMedica. - 2017. - Vol. 7. - № 2. - P. 111-117.

6. Shkarin V.V., Domenyuk D.A., Porfiriadis M.P., DMitrienko D.S., DMitrienko S.V. Mathematical and graphics simulation for individual shape of maxillary dental arch // Archiv Euro-Medica, 2017. Vol. 7. - № 1. - P. 60-65. 